Article

\title{
Electromagnetic Performance Evaluation of an Outer-Rotor Flux-Switching Permanent Magnet Motor Based on Electrical-Thermal Two-Way Coupling Method
}

\author{
Zhengming Shu ${ }^{1}$, Xiaoyong Zhu ${ }^{1,2, *}$, Li Quan $^{1,2}$, Yi Du ${ }^{1}$ and Chang Liu ${ }^{1}$ \\ 1 School of Electrical and Information Engineering, Jiangsu University, Zhenjiang 212013, China; \\ shuzhengming90@163.com (Z.S.); quanli@ujs.edu.cn (L.Q.); duyie@ujs.edu.cn (Y.D.); \\ LiuchangAlex49@163.com (C.L.) \\ 2 Jiangsu Key Laboratory of Drive and Intelligent Control for Electric Vehicle, Jiangsu University, \\ Zhenjiang 212013, China \\ * Correspondence: zxyff@ujs.edu.cn; Tel.: +86-511-8879-1245; Fax: +86-511-8878-0088
}

Academic Editors: Joeri Van Mierlo and Omar Hegazy

Received: 16 March 2017; Accepted: 8 May 2017; Published: 12 May 2017

\begin{abstract}
Flux-switching permanent magnet (FSPM) motors have gained increasing attention in electric vehicles (EVs) applications due to the advantages of high power density and high efficiency. However, the heat sources of both permanent magnet (PM) and armature winding are located on the limited stator space in the FSPM motors, which may result in the PM overheating and irreversible demagnetization caused by temperature rise, and it is often ignored in the conventional thermal analysis. In this paper, a new electrical-thermal two-way coupling design method is proposed to analyze the electromagnetic performances, where the change of PM material characteristics under different temperatures is taken into consideration. First, the motor topology and design equations are introduced. Second, the demagnetization curves of PM materials under different temperatures are modeled due to PM materials are sensitive to the temperature. Based on the electrical-thermal two-way coupling method, the motor performances are evaluated in detail, such as the load PM flux linkage and output torque. The motor is then optimized, and the electromagnetic performances between initial and improved motors are compared. Finally, a prototype motor is manufactured, and the results are validated by experimental measurements.
\end{abstract}

Keywords: electrical-thermal two-way coupling; flux-switching permanent magnet motor; thermal analysis; permanent magnet material characteristics

\section{Introduction}

With the increasing development of the electric vehicles (EVs), outer-rotor in-wheel motors have been considered as one of the promising candidates because they can offer the potential superior features of quick torque response, weight reduction, and compact vehicle space [1-4].

Meanwhile, permanent magnet motors have potential applications in EVs due to the advantages of high power density and high efficiency [5]. In recent years, the flux-switching permanent magnet (FSPM) motors where permanent magnets locate on the stator, which also have the advantages of high power density and high efficiency. Therefore, FSPM motors have been investigated extensively [6-11]. The rotor structure is simple in this type of motor, with neither permanent magnets nor winding, and the rotor inertia is small, so they are suitable for high-speed operation and have potential applications in EVs [12]. In this paper, by incorporating the concept of the outer-rotor in-wheel motor into the FSPM motor, an outer-rotor in-wheel FSPM motor is investigated, where one significant 
difference of the motor configuration lies in the magnets being placed in the stator with two magnet pieces per pole. By the V-shaped placement of adjacent PMs, the flux-focusing effects can be realized, which are able to increase the flux density in the air gap. However, flux-focusing effects may cause the loss of each element easily increased, which further results in the raise of the temperature. In addition, the PMs are embedded in the stator core and surrounded by the concentrated armature windings in the FSPM motor [13-15], both of which are heat sources. The concentrated heat sources may make the PMs overheated and cause irreversible demagnetization, which inevitably affects motor performance. Therefore, the thermal analysis, particularly the methods to analyze the electromagnetic performances based on the different PM material characteristics under different temperatures, is an indispensable part of the process of motor design to ensure safe operation.

Currently, several methods for thermal analysis have been investigated in the literature. In [16-18], the conventional finite element analysis (FEA) method is applied: it offers the advantages of simulating complex motor structure and the temperature distributions of heat sources. However, with the raise in temperature, the change of PM material characteristics is ignored in that method. As a result, the inaccurate results cannot meet the desirable requirements. To obtain accurate results, the iterative parameter method is analyzed in [19], which can efficiently improve the accuracy of results, as the parameter needs to be calculated through multiple iterations in the simulation program. However, the simulation process involves $2 \mathrm{D}$ and $3 \mathrm{D}$ simulations, which are inconvenient, especially for the complex motor structure. In $[20,21]$, the lumped parameter method is considered as an effective way to realize the thermal analysis because it can offer fast and simple computation and also considers different heat-transfer mechanisms, but only the components' temperature distributions (rather than those of the whole motor) are obtained in that method.

In this paper, a new electrical-thermal two-way coupling design method is proposed to analyze the electromagnetic performances based on the investigated FSPM motor, where the change of PM material characteristics under different temperatures is taken into consideration. First, the motor topology is introduced, and the design equations are also deduced. Second, the demagnetization curves of PMs under different temperatures are modeled, and by implementing the electrical-thermal two-way coupling method, the load PM flux linkage and output torque are analyzed in details. Then, based on this, the motor is optimized, and the electromagnetic performances between initial and improved motors are compared. Finally, a prototype motor is manufactured and tested for experimental validation.

\section{Motor Topology and Design Equation}

\subsection{Motor Topology}

Figure 1 shows the configuration of the $6 / 22$ stator/rotor pole outer-rotor V-shaped flux-switching permanent magnet (V-FSPM) motor. It can be observed that each stator pole of the outer-rotor FSPM motor is embedded in two PMs and wound concentrated armature windings, while the rotor pole is simple, with 22 iron teeth. Compared with the conventional 12/10 stator/rotor pole FSPM motor [22], the stator pole number of the outer-rotor FSPM motor is reduced by half with only six poles. Thus, the stator slot area can be increased under the same dimension size. Meanwhile, the magnets are placed in the stator with two magnet pieces per pole, which can enhance the flux-focusing effects and further increase the flux density in the air gap. In addition, the rotor pole is only formed with silicon steel sheets, thus the simple rotor configurations reduce manufacture difficulty and ensure the reliability of the motor. Meanwhile, high torque at low speed can be facilitated in the V-FSPM motor due to the high rotor pole numbers arrangement. 


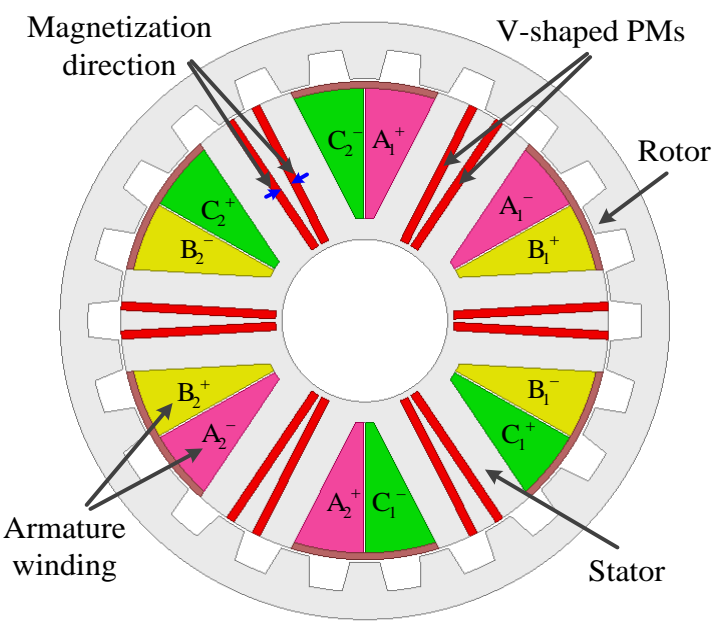

Figure 1. Configurations of the V-shaped flux-switching permanent magnet (V-FSPM) motor.

\subsection{Design Equations}

For the investigated FSPM motor, the feasible combinations of stator and rotor pole numbers can be determined through analysis and calculation. Since the magnetization direction of adjacent PMs is face-to-face, the stator pole number should be even. Meanwhile, the stator pole numbers should be a multiple of the phase number in the three-phase motor. Therefore, the stator pole number should be a multiple of 6 . Then, the feasible combinations of stator and rotor pole numbers can be given by,

$$
N_{s}=6 k_{1} \text { and } N_{r}=k_{2} N_{s} \pm k_{3}
$$

where $N_{r}$ is the number of rotor poles, $N_{s}$ is the number of stator poles, and $k_{1}, k_{2}$, and $k_{3}$ are positive integers. It is worthwhile to mention that $N_{r}$ is preferred to be even number so that the unbalanced magnetic force can be efficiently avoided.

The dimension design of the FSPM motor has its inherent standards. Based on the conventional design method, the design equation of the V-FSPM motor can be deduced as,

$$
Q_{\text {out }}\left(T_{\text {ref }}\right)=\frac{\sqrt{2} \pi^{3}}{4} \frac{N_{r}}{N_{s}} D^{2}{ }_{\text {so }} l_{a} k_{s} k_{d} k_{\text {sio }}^{2} A_{s} B_{\text {gmax }} c_{s} \eta
$$

In order to improve readability, all the coefficients in Equation (2) have been defined in Table 1.

\begin{tabular}{|c|c|}
\hline Symbols & Descriptions \\
\hline$D_{\text {so }}$ & Stator outer diameter \\
\hline$l_{a}$ & Stack length of the motor \\
\hline$k_{s}$ & $\begin{array}{l}\text { Chute coefficient, which is the cosine relation between the rotor chute } \\
\text { angle and the stator tooth distance }\end{array}$ \\
\hline$k_{d}$ & $\begin{array}{l}\text { Magnetic flux leakage coefficient, which is the ratio of the effective flux } \\
\text { in the turns of the winding to the air gap flux }\end{array}$ \\
\hline$k_{\text {sio }}$ & The ratio of inside diameter and outside diameter of the stator \\
\hline$A_{S}$ & Line load of the armature windings \\
\hline$B_{g \max }$ & The peak air gap flux density at no-load condition \\
\hline$c_{S}$ & $\begin{array}{l}\text { The pole arc coefficient of stator tooth, which is the ratio of stator tooth } \\
\text { pole arc width to stator pole pitch }\end{array}$ \\
\hline$\eta$ & Efficiency, which is the ratio of the output power to the input power \\
\hline$T_{\text {ref }}$ & The reference temperature \\
\hline$Q_{\text {out }}\left(T_{\text {ref }}\right)$ & The output torque at the reference temperature \\
\hline
\end{tabular}

Table 1. The definitions of all the coefficients. 
Because the output torque is sensitive to the temperature variation, a temperature scaling factor $K_{\text {temp }}$ is introduced, which can be expressed as,

$$
K_{\text {temp }}=\frac{Q_{o u t}(T)}{Q_{o u t}\left(T_{r e f}\right)}
$$

where $T$ is temperature, $Q_{o u t}(T)$ is the output torque at the temperature $T$. In the conventional method [23], the value of $K_{\text {temp }}$ equals 1 because the temperature impact is ignored. When temperature rise is considered, the value of $K_{\text {temp }}$ is supposed to be less than 1 . It can be easily seen that in order to obtain high output torque at the temperature $T$, a high value of $K_{\text {temp }}$ is needed.

\section{Electrical-Thermal Two-Way Coupling Method}

\subsection{Characteristics of PM Material}

The permanent magnet materials are sensitive to the temperature, which results in the PM suffering from performance reduction and even irreversible demagnetization when the motor operates at the high temperatures. Therefore, it is necessary to obtain the demagnetization curves of PM materials under different temperatures.

First, the PM intrinsic $B_{i}$-H curve at a certain reference temperature is provided by the material supplier, among them, $B_{i}$ denotes the PM magnetization. The remanence and the intrinsic coercive force at the reference temperature can be obtained easily. Based on this, the remanence $B_{r}(T)$ and the intrinsic coercive force $H_{c i}(T)$ at different temperatures can be derived as [24],

$$
\left\{\begin{array}{l}
B_{r}(T)=B_{r}\left(T_{r e f}\right) \cdot\left[1+\alpha\left(T-T_{r e f}\right)\right] \\
H_{c i}(T)=H_{c i}\left(T_{r e f}\right) \cdot\left[1+\beta\left(T-T_{r e f}\right)\right]
\end{array}\right.
$$

where $B_{r}\left(T_{r e f}\right)$ and $H_{c i}\left(T_{r e f}\right)$ are the remanence and the intrinsic coercive force at the reference temperature, $\alpha$ and $\beta$ are temperature coefficients. The values of $\alpha$ and $\beta$ are -0.0010876 and -0.00647425 , which are obtained by linear least square method. The PM material of NdFeB is used in this paper. The bulk conductivity and remanence are $625,000 \mathrm{~S} / \mathrm{m}$ and $1.45 \mathrm{~T}$, respectively. The reference $B_{i}-\mathrm{H}$ curve is modeled in Table 2, which is provided by material supplier. Table 2 is shown as follows:

Table 2. Reference $B_{i}$-H curve values.

\begin{tabular}{ccccccccc}
\hline Number & $\boldsymbol{H}$ & $\boldsymbol{B}_{\boldsymbol{i}}$ & Number & $\boldsymbol{H}$ & $\boldsymbol{B}_{\boldsymbol{i}}$ & Number & $\boldsymbol{H}$ & $\boldsymbol{B}_{\boldsymbol{i}}$ \\
\hline 1 & $-874,891$ & 0 & 14 & $-810,209$ & 1.29581 & 27 & $-389,779$ & 1.440634 \\
2 & $-872,185$ & 0.104417 & 15 & $-777,868$ & 1.3465 & 28 & $-357,438$ & 1.442663 \\
3 & $-870,323$ & 0.196823 & 16 & $-745,528$ & 1.373112 & 29 & $-325,098$ & 1.444691 \\
4 & $-868,294$ & 0.305071 & 17 & $-713,187$ & 1.392021 & 30 & $-292,757$ & 1.445884 \\
5 & $-866,591$ & 0.405398 & 18 & $-680,846$ & 1.40616 & 31 & $-260,416$ & 1.446921 \\
6 & $-864,729$ & 0.505725 & 19 & $-648,505$ & 1.415546 & 32 & $-228,075$ & 1.447947 \\
7 & $-862,867$ & 0.603412 & 20 & $-616,164$ & 1.422242 & 33 & $-195,734$ & 1.448959 \\
8 & $-861,004$ & 0.703739 & 21 & $-583,824$ & 1.426483 & 34 & $-163,394$ & 1.44997 \\
9 & $-859,142$ & 0.811986 & 22 & $-551,483$ & 1.430411 & 35 & $-131,053$ & 1.450959 \\
10 & $-857,272$ & 0.904392 & 23 & $-519,142$ & 1.43348 & 36 & $-98,712.1$ & 1.451946 \\
11 & $-855,410$ & 1.00472 & 24 & $-486,801$ & 1.43655 & 37 & $-66,371.3$ & 1.4524 \\
12 & $-849,824$ & 1.09976 & 25 & $-454,461$ & 1.438146 & 38 & $-34,030.5$ & 1.45242 \\
13 & $-842,550$ & 1.174 & 26 & $-422,120$ & 1.43921 & 39 & 0 & 1.45244 \\
\hline
\end{tabular}


Second, since the PM intrinsic $B_{i}-H$ curves at different temperatures have very similar shape, the intrinsic $B_{i}-H$ curves can be adjusted to one curve (more or less) after the normalized scaling, the normalized intrinsic $b_{i}$ - $h$ curve can be given by,

$$
\left\{\begin{array}{l}
b_{i}(T)=B_{i}(T) / B_{r}(T) \\
h_{i}(T)=H_{i}(T) / H_{c i}(T)
\end{array}\right.
$$

where $b_{i}(T)$ and $h_{i}(T)$ are the flux density and magnetic field intensity on the normalized intrinsic $b_{i}-h$ curves at the temperature $T . B_{i}(T)$ and $H_{i}(T)$ are the flux density and magnetic field intensity on the original intrinsic $B_{i}-H$ curves at the temperature $T$. From Equation (5), the normalized intrinsic $b_{i}-h$ curve at any temperature $T$ can be obtained.

All the intrinsic $B_{i}-H$ curves at different temperatures are normalized to one curve, thus the normalized intrinsic $b_{i}-h$ curve applies to all temperatures. To facilitate the calculation, the normalized intrinsic $b_{i}-h$ curve at the reference temperature is selected. Then, Equation (5) at the reference temperature can be expressed as,

$$
\left\{\begin{array}{l}
b_{i}\left(T_{r e f}\right)=B_{i}\left(T_{r e f}\right) / B_{r}\left(T_{r e f}\right) \\
h_{i}\left(T_{r e f}\right)=H_{i}\left(T_{r e f}\right) / H_{c i}\left(T_{r e f}\right)
\end{array}\right.
$$

Even though the selected normalized intrinsic $b_{i}-h$ curve is generated using the reference temperature, it is valid for all temperatures because of the very similar shape. Then the intrinsic $B_{i}-H$ curves can be given by,

$$
\left\{\begin{array}{l}
B_{i}(T)=b_{i}\left(T_{r e f}\right) \cdot B_{r}(T) \\
H_{i}(T)=h_{i}\left(T_{r e f}\right) \cdot H_{c i}(T)
\end{array}\right.
$$

In this paper, the PM of $\mathrm{NdFeB}$ material is employed and the corresponding intrinsic $B_{i}-H$ curve at the reference temperature $\left(20^{\circ} \mathrm{C}\right)$ is provided by the supplier. According to the above analysis, the intrinsic $B_{i}-H$ curves at different temperatures can be established successfully, which is shown in Figure 2a. It can be seen that the temperature variations have important effects on the PM characteristics, and the PM performance reduces when the temperature rises. This inevitably leads to the inaccuracy of the analysis results when the rise in temperature is ignored. The corresponding normalized intrinsic $b_{i}$ - $h$ curve is shown in Figure $2 \mathrm{~b}$.

Finally, in the finite element analysis, the required $B-H$ curves of PM can be efficiently transformed from the $B_{i}-H$ curves in Equation (7), the corresponding transformed equation can be expressed as,

$$
\left[\begin{array}{c}
B \\
H
\end{array}\right]=\left[\begin{array}{cc}
1 & \mu_{0} \\
0 & 1
\end{array}\right] \cdot\left[\begin{array}{c}
B_{i} \\
H_{i}
\end{array}\right]
$$

where $\mu_{0}$ is vacuum permeability.

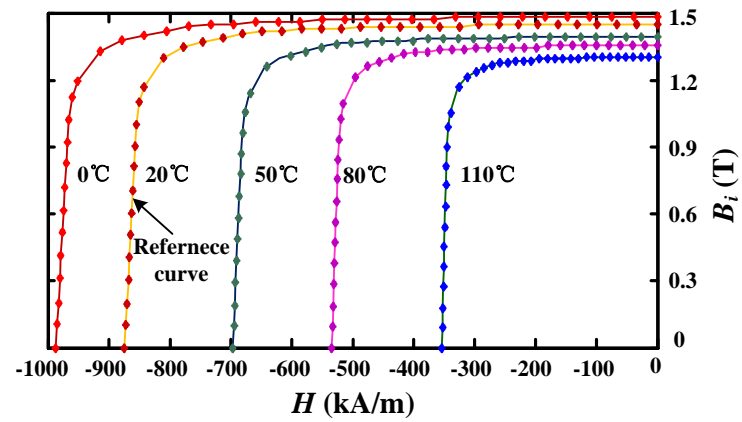

(a)

Figure 2. Cont. 


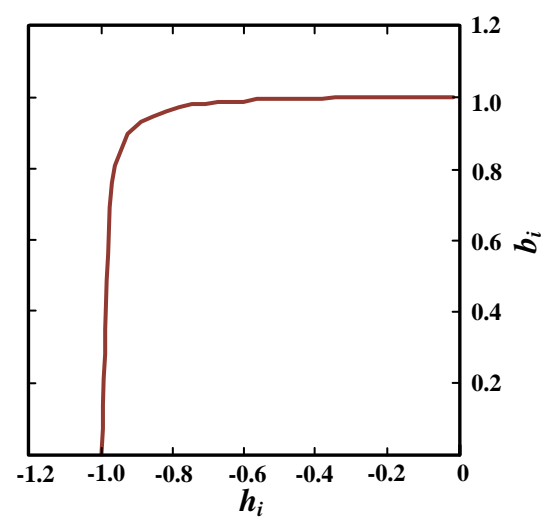

(b)

Figure 2. Curves. (a) $B_{i}-H$ curves at different temperatures; (b) Normalized intrinsic $b_{i}-h$ curve.

\subsection{The Flow Chart of the Proposed Method}

Figure 3a shows the flow chart of the single-way method. The single-way method mainly focuses on temperature calculation. First, the 2D FEM model and 3D CFD model are built. Then, the losses can be obtained from electromagnetic performance analysis based on the 2D FEM model. After that, the losses are imported to the 3D CFD model to calculate temperature. The residual can be used as an indicator to judge whether the motor reaches steady state in the fluent program, which is decreased with the increase of the iterations. If the residual drops to below the given order of magnitudes, it can be considered that the motor reaches the steady state and steady-state temperature distribution can be acquired. Otherwise, temperature calculation should be continued until the residual satisfies the convergence requirements.

Figure $3 \mathrm{~b}$ shows the flow chart of the proposed method. The method mainly consists of the following five steps:

Step 1 Construct the 2D finite element analysis model and 3D thermal model according the motor configuration.

Step 2 The losses of each element are respectively calculated in the electromagnetic solver based on the demagnetization curve at the operating temperature. Then, the acquired losses used as the thermal source are imported into the thermal solver, and the temperature distribution can be obtained. Generally, the results between the obtained temperature and original operating temperature cannot achieve convergence. Because the original temperature is a reference temperature, it may not be the ideal temperature. The obtained temperature is relatively high after loss calculation. For example, as shown in Table 3, the temperature difference of the first time single-way coupling is $65.2^{\circ} \mathrm{C}$, which is far higher than temperature difference $0.8^{\circ} \mathrm{C}$ by second time single-way coupling. Thus, the relatively large temperature difference can be generally considered no convergence.

Step 3 Alternatively, the temperature results are fed back to the electromagnetic solver by updating the material properties under the corresponding temperature. Then, the new loss results can be obtained by the electromagnetic performance analysis.

Step 4 Import the new loss results into the thermal solver to get the new temperature distribution. The temperature convergence can be estimated according to the two temperature results from the thermal solver. If the difference value of the two adjacent temperature results is within the setting threshold, the two-way coupling analysis is completed. Otherwise, return to step 3.

Step 5 Feed back to the design by optimizing the motor and evaluating the motor's electromagnetic performances. After optimization, if the electromagnetic performances meet the required demands, the motor dimensions can be determined. Otherwise, the dimension parameters need to be further optimized. 

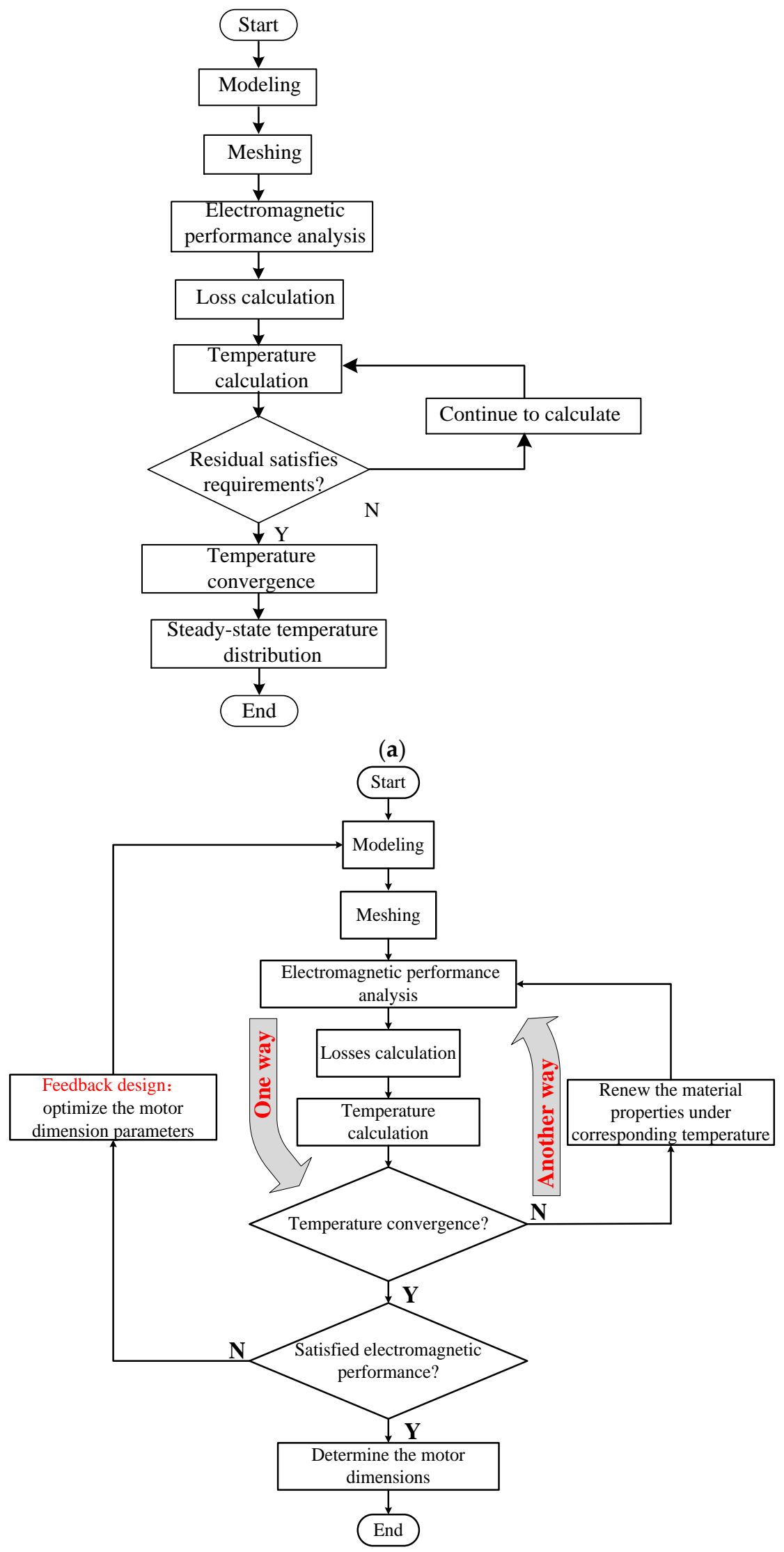

(b)

Figure 3. Flow chart of two methods. (a) Single-way method; (b) The proposed method. 
Table 3. Temperature convergence tracks.

\begin{tabular}{|c|c|c|c|c|c|c|c|c|}
\hline \multirow{2}{*}{\multicolumn{2}{|c|}{ Analysis Method }} & \multicolumn{7}{|c|}{ Iteration Times } \\
\hline & & \multirow{3}{*}{$\begin{array}{c}0 \\
20 \\
-\end{array}$} & \multirow{3}{*}{$\begin{array}{c}\mathbf{1 0} \\
85.2 \\
65.2\end{array}$} & \multirow{3}{*}{$\begin{array}{c}20 \\
86 \\
0.8\end{array}$} & \multirow{3}{*}{$\begin{array}{c}30 \\
86 \\
0\end{array}$} & \multirow{3}{*}{$\begin{array}{c}40 \\
86 \\
0\end{array}$} & \multirow{3}{*}{$\begin{array}{c}\mathbf{5 0} \\
86 \\
0\end{array}$} & \multirow{3}{*}{$\begin{array}{c}\ldots \ldots \\
86 \\
0\end{array}$} \\
\hline & Temperature $\left({ }^{\circ} \mathrm{C}\right)$ & & & & & & & \\
\hline Singre-way & Temperature difference $\left({ }^{\circ} \mathrm{C}\right)$ & & & & & & & \\
\hline \multirow{2}{*}{ Two-way coupling } & Temperature $\left({ }^{\circ} \mathrm{C}\right)$ & 20 & 86 & 102 & 97.3 & 98 & 98 & 98 \\
\hline & Temperature difference $\left({ }^{\circ} \mathrm{C}\right)$ & - & 66 & 16 & 4.7 & 0.7 & 0 & 0 \\
\hline
\end{tabular}

\section{Electrical-Thermal Two-Way Coupling Analysis}

After the introduction of the electrical-thermal two-way coupling method flowchart, the performances and the rise in temperature are respectively analyzed in the conventional single-way method (without coupling) and via the proposed method (with the electrical-thermal two-way coupling).

The temperature convergence results of two methods are shown in Table 3. The temperature rises with the increase of iteration time and reaches the steady state after multiple iterations. In the single-way analysis, the temperature reaches the steady state after 20 times iteration, while the two-way coupling analysis reaches the steady state after 40 times iteration. At this time, the convergence temperatures of them are respectively converged with the $86^{\circ} \mathrm{C}$ and $98{ }^{\circ} \mathrm{C}$, indicating that the effect of the temperatures on PM material is effectively considered.

In this paper, the temperature calculation is based on the 3D CFD model. The corresponding 3D steady-state heat conduction equation based on the basic laws of heat transfer is given as,

$$
\frac{\partial}{\partial x}\left(k_{x} \frac{\partial T}{\partial x}\right)+\frac{\partial}{\partial y}\left(k_{y} \frac{\partial T}{\partial y}\right)+\frac{\partial}{\partial z}\left(k_{z} \frac{\partial T}{\partial z}\right)=-q
$$

where $k_{x}, k_{y}$, and $k_{z}$ are the coefficient of the heat conductivity in $x$-, $y$ - and $z$-direction, respectively, $q$ is the density of heat source.

Three kinds of boundary conditions are shown as follows:

$$
\left\{\begin{array}{l}
\left.T\right|_{S 1}=T_{0} \\
-\left.\lambda \frac{\partial T}{\partial n}\right|_{S 2}=q_{0} \\
-\left.\lambda \frac{\partial T}{\partial n}\right|_{S 3}=\delta\left(T-T_{\mathrm{re} f}\right)
\end{array}\right.
$$

where $S_{1}, S_{2}$, and $S_{3}$ are three kinds of boundary surfaces. $\lambda$ is the coefficient if the heat conductivity. $T_{0}$ and $q_{0}$ are the known boundary temperature and given heat flux density flowing out from the boundary. $\delta$ is the convective heat transfer coefficient. The material properties are shown in Table 4 .

Table 4. Material properties.

\begin{tabular}{cccc}
\hline Material & Density $\left[\mathrm{kg} \cdot \mathbf{m}^{-3}\right]$ & Specific Heat $\left[\mathbf{J} /\left(\mathbf{k g}{ }^{\circ} \mathbf{C}\right)\right]$ & Thermal Conductivity $\left[\mathbf{W} /\left(\mathbf{m}^{\circ} \mathbf{C}\right)\right]$ \\
\hline Copper & 8978 & 381 & 387.6 \\
NdFeB & 7500 & 450 & 9 \\
Silicon Steel & 7872 & 426 & 40 \\
Insulation & 1300 & 1400 & 0.3 \\
Aluminum & 2719 & 871 & 202.4 \\
\hline
\end{tabular}

The temperature distributions of the motor by the two methods are shown in Figure 4a. The temperature with the two-way coupling is higher than that of the conventional single-way method, which indicates that the losses of the motor are increased due to the temperature rise after coupling. Moreover, the highest temperature occurs at the stator teeth due to the concentrated heat sources on the stator. The raise of temperature with coupling will degrade the remanence and the 
coercive force, which cause the variation of field distribution, especially when the armature current is applied, as shown in Figure $4 \mathrm{~b}$. This will further lead to electromagnetic performances variations, such as load PM flux linkage and output torque.

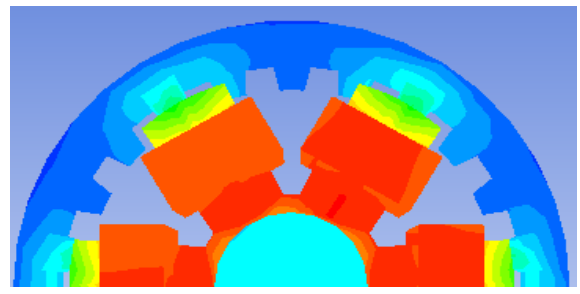

Single-way

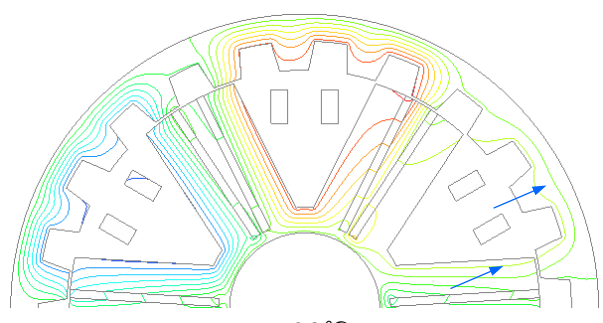

$20^{\circ} \mathrm{C}$

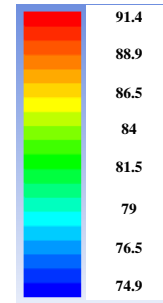

(a)

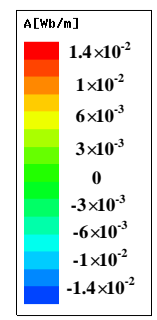

(b)

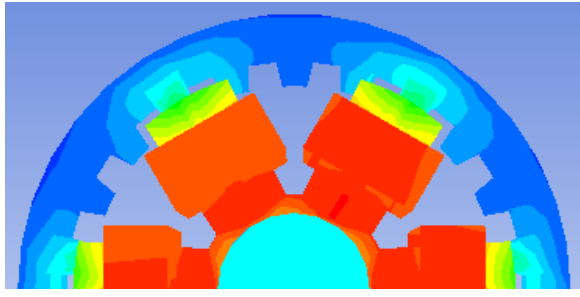

Two-way coupling

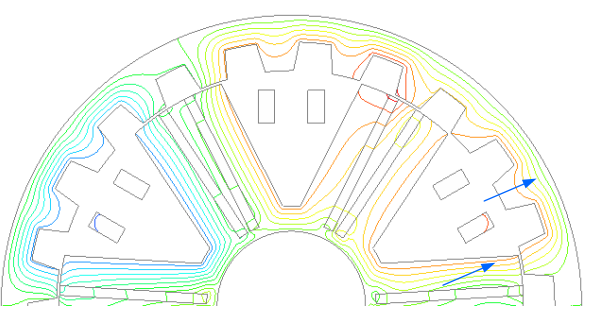

$98^{\circ} \mathrm{C}$

Figure 4. Comparison results. (a) Temperature distributions; (b) Field distributions.

Figure 5a shows the comparison results of the load PM flux linkage by the two methods. It can be observed that the peak value of the load PM flux linkage is $0.278 \mathrm{~Wb}$ at the reference temperature $20^{\circ} \mathrm{C}$, while the peak value is increased to $0.293 \mathrm{~Wb}$ at two-way coupling temperature of $98^{\circ} \mathrm{C}$, the slightly increase of the load PM flux linkage is resulted by the raise of temperature after coupling, since the iron saturation degree is reduced due to the degraded PM remanence and coercive force when the temperature rises. Figure $5 \mathrm{~b}$ shows the comparison results of output torque. Obviously, due to the temperature rise, the output torque reduced from $26.21 \mathrm{Nm}$ to $20.18 \mathrm{Nm}$, which offer a design guide for the following feedback design.

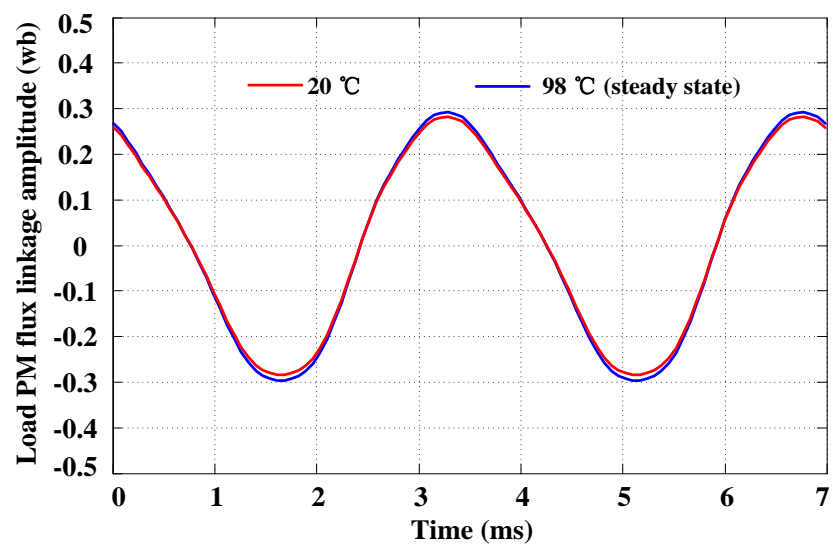

(a)

Figure 5. Cont. 


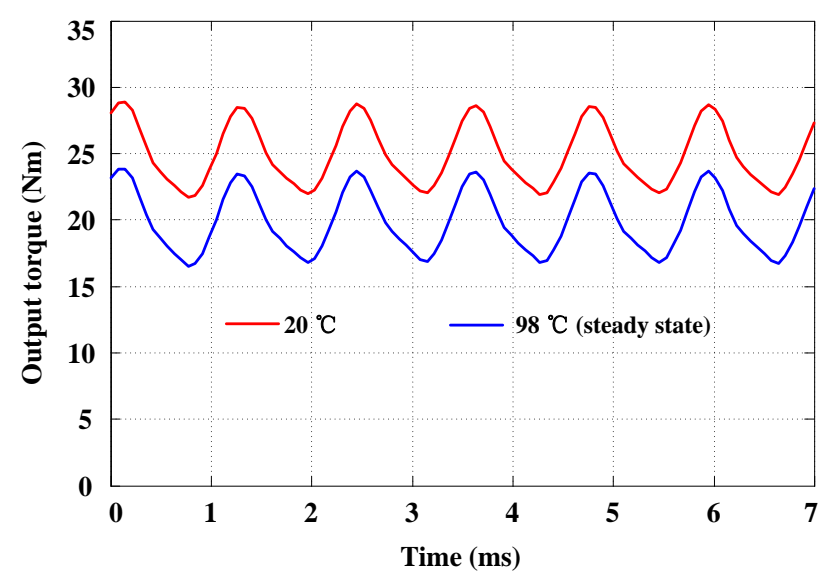

(b)

Figure 5. Comparison results of electromagnetic performances. (a) Load permanent magnet (PM) flux linkage; (b) Output torque.

\section{Motor Optimization}

It is illustrated that the aforementioned electromagnetic performances are often degraded during the temperature rise, which results in that the actual performances generally cannot meet the final requirements. Therefore, in order to improve the motor performance accuracy, the feedback design of the V-FSPM motor is needed. According to Figure 3b, the feedback design of optimization is implemented after the two-way coupling analysis.

The structure of the investigated V-FSPM motor is relatively complex. As a result, the numbers of motor parameters are relatively large. Considering that rotor tooth width, stator tooth width, PM width, and V-shaped angle of two PMs are the leading parameters in design process for the V-FSPM motor, and the V-shaped angle of two PMs exhibits significant influence on motor performances [25]. Therefore, the placed angle of two PMs $\beta_{v s}$ is selected as a key parameter to be optimized as an example in this section.

In the V-FSPM motor, the V-shaped placement of PMs can enhance the flux-focusing effects and improve the output torque. Since the load PM flux linkage directly affects the capacity of output torque, the relationship between the placed angle of the two PMs $\beta_{v s}$ and the load PM flux linkage needs to be analyzed. Besides, the cogging torque is an important electromagnetic performance for EVs applications, so the relationship between the placed angle $\beta_{v s}$ and the peak-to-peak (P-P) cogging torque should also be investigated. Figure 6 shows the variation of flux linkage and cogging torque with the change of the angle of the V-shaped PMs. As shown in Figure 6, the cogging torque decreases with the increase of $\beta_{v s}$ from 2 to 5 degrees and reaches the minimum value when $\beta_{v s}$ equals to 5 degrees. Meanwhile, the load PM flux linkage amplitude possesses a low increase with the raise of $\beta_{v s}$ from 5 to 7 degrees. When $\beta_{v s}$ increases from 7 to 9 degrees, the load PM flux linkage amplitude decreases mainly due to the saturation effect in stator tooth. Considering a compromise design between the high PM flux linkage amplitude and the low cogging torque, $\beta_{v s}$ is chosen to be 5 degrees. Then, some key design parameters are listed in Table 5.

Based on the adjusted sizes of the design parameters, the electromagnetic performances of the V-FSPM motor between initial and improved motors are compared in details.

The results with the two-way coupling are shown in Figure 7, including temperature distribution and field distribution. Figure 7a shows the temperature distribution with two-way coupling after optimization. The temperature at the same load current is decreased. Meanwhile, Figure $7 \mathrm{~b}$ shows the field distribution after optimization. The field intensity, after the feedback design, is slightly increased. 


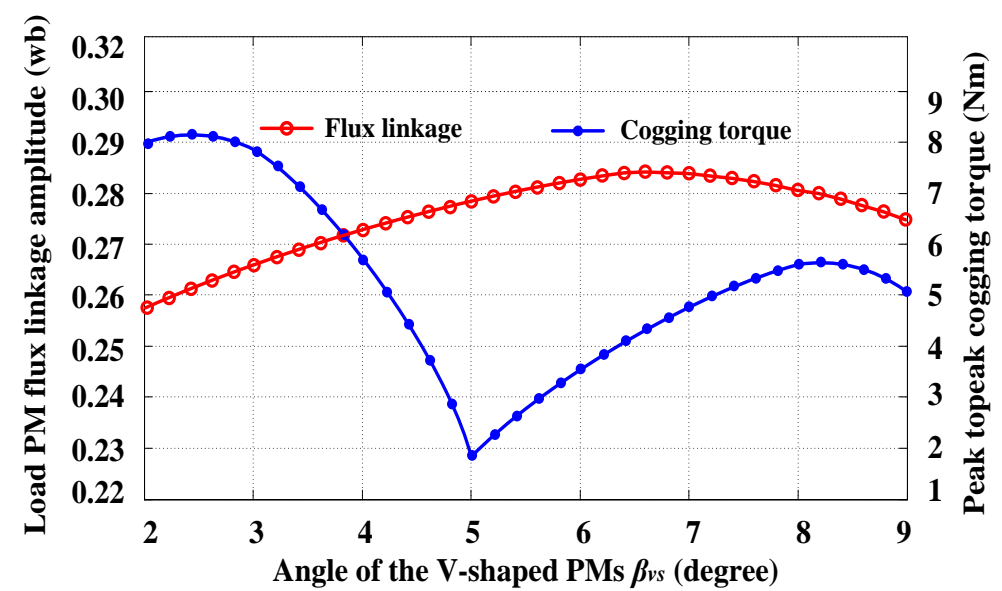

Figure 6. Variation of load PM flux linkage and peak to peak cogging torque with respect to the angle of the V-shaped PMs.

Table 5. Key design parameters.

\begin{tabular}{ccc}
\hline Parameters & Values & Unit \\
\hline Rotor pole arc width & 6 & degree \\
Rotor teeth height & 8 & $\mathrm{~mm}$ \\
Rotor teeth arc width at yoke & 10 & degree \\
Air gap length & 0.8 & $\mathrm{~mm}$ \\
Placed angle of the two PMs & 5 & degree \\
PM arc width & 2 & degree \\
Stator yoke radius & 30 & mm \\
Stator yoke arc width & 10 & degree \\
Stator inner radius & 22.4 & $\mathrm{~mm}$ \\
\hline
\end{tabular}

\begin{tabular}{|c|}
\hline 91.4 \\
\hline 88.9 \\
\hline 86.5 \\
\hline 84 \\
\hline 81.5 \\
\hline 79 \\
76.5 \\
\hline 74.9 \\
\hline
\end{tabular}
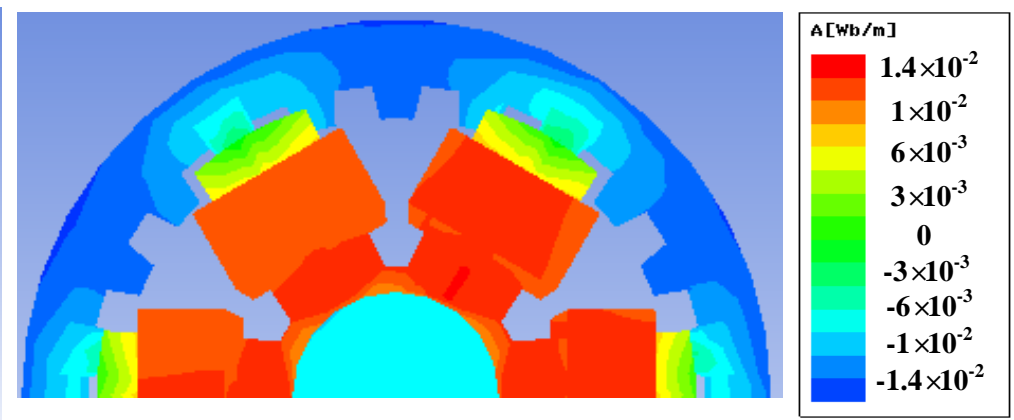

(a)

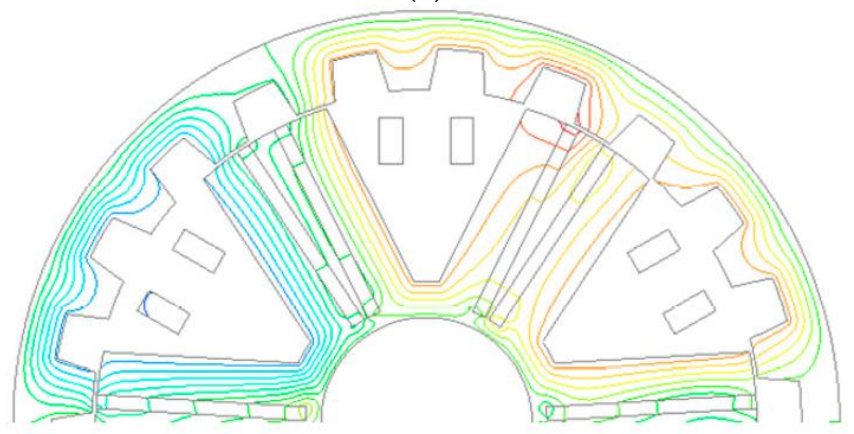

(b)

Figure 7. Optimization results at $91^{\circ} \mathrm{C}$ after optimization. (a) Temperature distribution; (b) Filed distributions. 
The load PM flux linkage waveforms under the initial and improved motors before and after the feedback design are respectively compared, as shown in Figure 8a. It can be found that the peak value of the load PM flux linkage after the feedback design is close to the values of initial motor. Figure $8 \mathrm{~b}$ shows the torque performances of the before and after the feedback design. It can be observed that the output torque after the feedback design at steady-state temperature of $91^{\circ} \mathrm{C}$ is increased to $22.35 \mathrm{Nm}$, which is increased by $10.75 \%$ compared with that before the feedback design. Meanwhile, the initial value of temperature scaling factor $K_{\text {temp }}$ is 0.79 , higher value of 0.88 is achieved after feedback design, which indicates that the performance of the motor after optimization is efficiently improved. The corresponding comparison results are listed in Table 6.

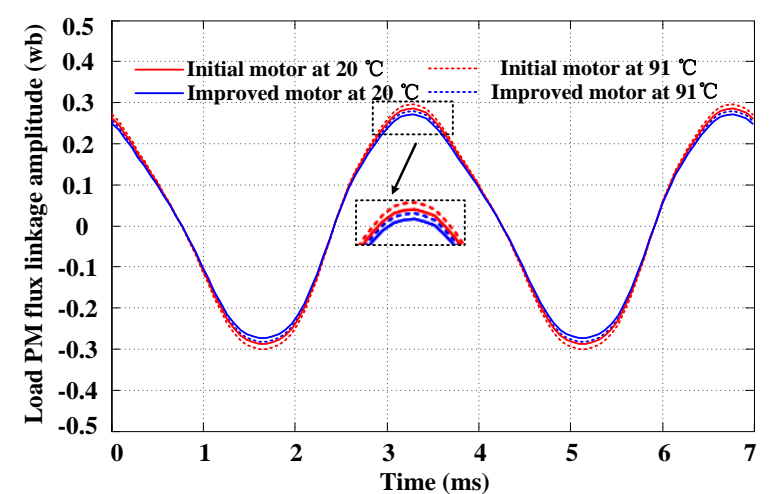

(a)

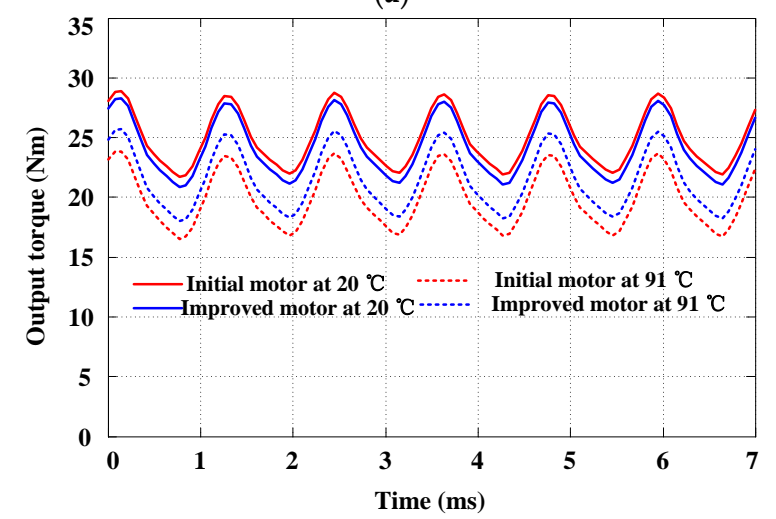

(b)

Figure 8. Comparison results of electromagnetic performances after optimization. (a) Load PM flux linkage; (b) Output torque.

Table 6. Comparisons results.

\begin{tabular}{|c|c|c|c|c|}
\hline Parameters & Unit & \multicolumn{2}{|c|}{ Initial Value } & Final Value \\
\hline PM arc width & deg & \multicolumn{2}{|c|}{3} & 2 \\
\hline Placed angle of the two PMs & deg & \multicolumn{2}{|c|}{5.5} & 5 \\
\hline Rotor pole arc width & deg & \multicolumn{2}{|c|}{8} & 6 \\
\hline Air gap length & $\mathrm{mm}$ & \multicolumn{2}{|c|}{0.6} & 0.8 \\
\hline Stator yoke arc width & deg & \multicolumn{2}{|c|}{9} & 10 \\
\hline Results & $\begin{array}{l}\text { Initial motor } \\
\text { at } 20^{\circ} \mathrm{C}\end{array}$ & $\begin{array}{l}\text { Initial motor } \\
\text { at } 91^{\circ} \mathrm{C}\end{array}$ & $\begin{array}{c}\text { Improved } \\
\text { motor at } 20^{\circ} \mathrm{C}\end{array}$ & $\begin{array}{c}\text { Improved } \\
\text { motor at } 91^{\circ} \mathrm{C}\end{array}$ \\
\hline Output torque $(\mathrm{Nm})$ & 26.21 & 20.18 & 25.49 & 22.35 \\
\hline$K_{\text {temp }}$ & - & 0.79 & - & 0.88 \\
\hline
\end{tabular}




\section{Experiment Validation}

In order to further verify the validity of the theoretical analysis, a prototype motor was manufactured according to the key design parameters in Table 5 . The rotor and stator of the prototype motor are shown in Figure 9a,b, and the experimental platform can be found in Figure 10. To obtain an experimental validation, the V-FSPM motor was driven continuously with a relatively long period of time to achieve an experiment of temperature rise. In this case, some fundamental experiments of the motor were carried out.

Figure 11 shows the steady-state torque and current waveforms under the $i_{d}=0$ control method, where $T_{e}, i_{a}, i_{b}$, and $i_{c}$ represent the waveforms of output torque for phase $\mathrm{A}$, phase $\mathrm{B}$, and phase $\mathrm{C}$ current, respectively. The applied phase current was $11 \mathrm{~A}$, and the output torque was $22.15 \mathrm{Nm}$. Meanwhile, the measured torque characteristics under different phase currents are shown in Figure 12. For comparison, the simulated results are also added in this figure. From the figure, it can be seen that the measured torques reasonably agree with the simulated values. The minor discrepancies between the measured and simulated results are mainly attributed to manufacturing error such as inaccurate air gap length and V-shaped PM width, the restrictions in experimental conditions, and measurement errors. In addition, the variation trends of the output torque at different currents are approximately linear, which implies that the motor possesses desirable over-load capabilities.

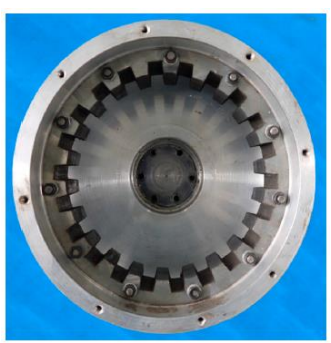

(a)

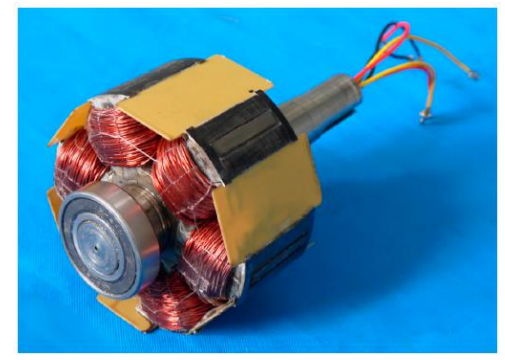

(b)

Figure 9. Prototype motor. (a) Rotor; (b) Stator.

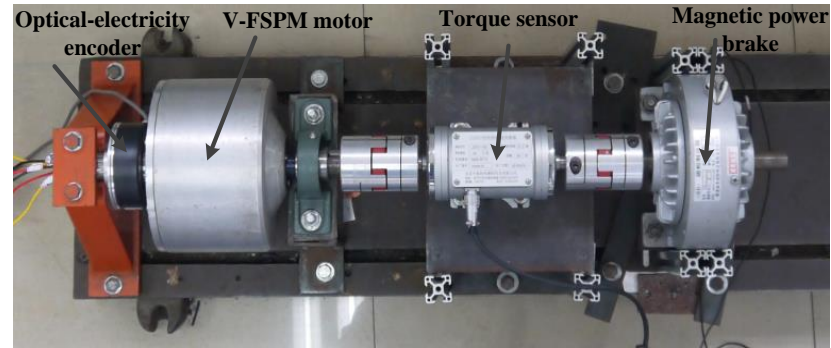

Figure 10. Experimental platforms.

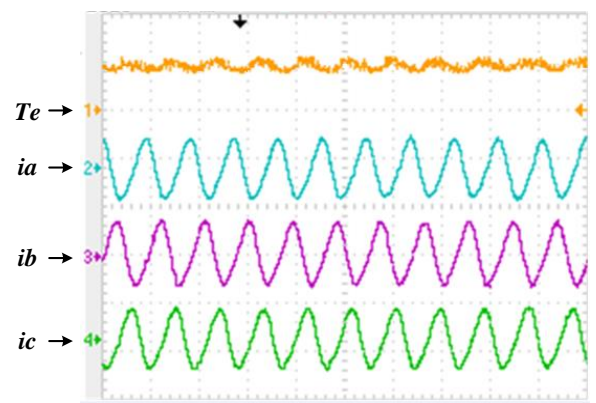

Figure 11. Steady-state torque and current waveforms ( $25 \mathrm{Nm} / \mathrm{div}, 15 \mathrm{~A} / \mathrm{div})$. 


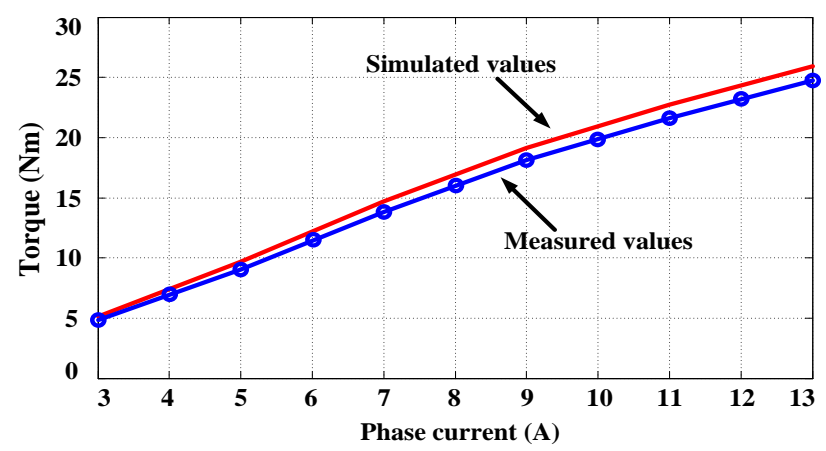

Figure 12. Measured and predicted torque versus different phase currents.

\section{Conclusions}

This paper proposes a new electrical-thermal two-way coupling design method to analyze electromagnetic performance where the change of PM material characteristics under different temperatures is taken into consideration. To illustrate the sensitive degree of PM materials to temperature variation, the demagnetization curves of PMs under different temperatures are modeled. By implementing the electrical-thermal two-way coupling method, the output torque is reduced compared with the conventional single-way method. Based on the performance characteristics, a feedback design is conducted purposefully through the adjustment of key design parameters. After the feedback design, the electromagnetic performances between initial and improved motors are compared. Finally, a prototype motor is manufactured to evaluate the performances of the V-PMFS motor. Both the simulation results and the experimental tests validate the correctness of the proposed method.

Acknowledgments: This work was supported by National Natural Science Foundation of China (Grant No. 51477069 and Grant No. 51377073), and in part by the Priority Academic Program Development of Jiangsu Higher Education Institutions.

Author Contributions: Xiaoyong Zhu conceived of the idea of the research and provided guidance and supervision. Zhengming Shu is the main author of this manuscript who implemented the research and performed the analysis. Li Quan, Yi Du and Chang Liu provided some useful suggestions in the construction of this paper. All the authors have contributed significantly to this work.

Conflicts of Interest: The authors declare no conflict of interest.

\section{References}

1. Chung, S.; Moon, S.; Kim, D.; Kim, J. Development of a 20-Pole-24-Slot SPMSM with Consequent Pole Rotor for In-Wheel Direct Drive. IEEE Trans. Ind. Electron. 2016, 63, 302-309. [CrossRef]

2. Ifedi, C.J.; Mecrow, B.C.; Brockway, S.T.M.; Boast, G.S.; Atkinson, G.J.; Kostic-Perovic, D. Fault-Tolerant In-Wheel Motor Topologies for High-Performance Electric Vehicles. IEEE Trans. Ind. Appl. 2013, 49, 1249-1257. [CrossRef]

3. Fei, W.Z.; Luk, P.C.K.; Shen, J.X.; Wang, Y.; Jin, M.J. A Novel Permanent-Magnet Flux Switching Machine with an Outer-Rotor Configuration for In-Wheel Light Traction Applications. IEEE Trans. Ind. Appl. 2012, 48, 1496-1506. [CrossRef]

4. Xue, X.D.; Cheng, K.W.E.; Ng, T.W.; Cheung, N.C. Multi-Objective Optimization Design of In-Wheel Switched Reluctance Motors in Electric Vehicles. IEEE Trans. Ind. Electron. 2010, 57, 2980-2987. [CrossRef]

5. Gu, W.W.; Zhu, X.Y.; Quan, L.; Du, Y. Design and optimization of permanent magnet brushless machines for electric vehicle applications. Energies 2015, 8, 13996-14008. [CrossRef] 
6. Zhu, X.Y.; Shu, Z.M.; Quan, L.; Xiang, Z.X.; Pan, X.Q. Multi-objective optimization of an outer-rotor V-shaped permanent magnet flux switching motor based on multi-level design method. IEEE Trans. Magn. 2016, 52, 1-8. [CrossRef]

7. Yin, J.N.; Zhu, X.Y.; Quan, L.; Zhang, C.; Xiang, Z.X. Comprehensive multi-objective secularization optimization of a permanent magnet machine with correlation parameters stratified method. IET Electr. Power Appl. 2017, 11, 72-79. [CrossRef]

8. Xiang, Z.X.; Zhu, X.Y.; Quan, L.; Du, Y.; Zhang, C.; Fan, D.Y. Multilevel Design Optimization and Operation of a Brushless Double Mechanical Port Flux-Switching Permanent-Magnet Motor. IEEE Trans. Ind. Electron. 2016, 63, 6042-6054. [CrossRef]

9. Du, Y.; Yang, G.; Quan, L.; Zhu, X.Y.; Xiao, F.; Wu, H.Y. Detent Force Reduction of a C-Core Linear Flux-Switching Permanent Magnet Machine with Multiple Additional Teeth. Energies 2017, 10, 318. [CrossRef]

10. Zhu, X.Y.; Xiang, Z.X.; Zhang, C.; Quan, L.; Du, Y.; Gu, W.W. Co-Reduction of Torque Ripple for Outer Rotor Flux-Switching PM Motor Using Systematic Multi-Level Design and Control Schemes. IEEE Trans. Ind. Electron. 2017, 64, 1102-1112. [CrossRef]

11. Hua, W.; Cheng, M.; Zhu, Z.Q.; Howe, D. Analysis and optimization of back EMF waveform of a flux-switching permanent magnet motor. IEEE Trans. Energy Convers. 2008, 23, 727-733. [CrossRef]

12. Raminosoa, T.; Gerada, C.; Galea, M. Design considerations for a fault-tolerant flux-switching permanent magnet machine. IEEE Trans. Ind. Electron. 2011, 58, 2818-2825. [CrossRef]

13. Lin, T.C.; Zhu, Z.Q.; Liu, K.; Liu, J.M. Improved Sensorless Control of Switched-Flux Permanent-Magnet Synchronous Machines Based on Different Winding Configurations. IEEE Trans. Ind. Electron. 2016, 63, 123-132. [CrossRef]

14. Zhu, Z.Q.; Chen, J.T.; Pang, Y.; Howe, D.; Iwasaki, S.; Deodhar, R. Analysis of a Novel Multi-Tooth Flux-Switching PM Brushless AC Machine for High Torque Direct-Drive Applications. IEEE Trans. Magn. 2008, 44, 4313-4316. [CrossRef]

15. Zhang, G.; Hua, W.; Cheng, M.; Liao, J.G.; Wang, K.; Zhang, J.Z. Investigation of an Improved Hybrid-Excitation Flux-Switching Brushless Machine for HEV/EV Applications. IEEE Trans. Ind. Appl. 2015, 51, 3791-3799. [CrossRef]

16. Li, G.G.; Ojeda, J.; Hoang, E.; Gabsi, M.; Lécrivain, M. Thermal-Electromagnetic Analysis for Driving Cycles of Embedded Flux-Switching Permanent-Magnet Motors. IEEE Trans. Veh. Technol. 2012, 61, 140-151. [CrossRef]

17. Chen, Y.Y.; Zhu, X.Y.; Quan, L.; Wang, L. Performance Analysis of a Double-Salient Permanent-Magnet Double-Rotor Motor Using Electromagnetic-Thermal Coupling Method. IEEE Trans. Appl. Supercond. 2016, 26, 5205305. [CrossRef]

18. Li, G.J.; Ojeda, J.; Hoang, E.; Gabsi, M. Thermal-electromagnetic analysis of a fault-tolerant dual-star flux-switching permanent magnet motor for critical applications. IET Electr. Power Appl. 2011, 5, 503-513. [CrossRef]

19. Sun, X.K.; Cheng, M.; Zhu, S.; Zhang, J.Z. Coupled Electromagnetic-Thermal-Mechanical Analysis for Accurate Prediction of Dual-Mechanical-Port Machine Performance. IEEE Trans. Ind. Appl. 2012, 48, 2240-2248. [CrossRef]

20. Thomas, A.S.; Zhu, Z.Q.; Li, G.J. Thermal Modelling of Switched Flux Permanent Magnet Machines. In Proceedings of the 2014 International Conference on Electrical Machines, Berlin, Germany, 2-5 September 2014; pp. 2212-2217.

21. Cai, X.H.; Cheng, M.; Zhu, S.; Zhang, J.W. Thermal Modeling of Flux-Switching Permanent-Magnet Machines Considering Anisotropic Conductivity and Thermal Contact Resistance. IEEE Trans. Ind. Electron. 2016, 63, 3355-3365. [CrossRef]

22. Cao, R.W.; Mi, C.; Cheng, M. Quantitative Comparison of Flux-Switching Permanent-Magnet Motors With Interior Permanent Magnet Motor for EV, HEV, and PHEV Applications. IEEE Trans. Magn. 2012, 48, 2374-2384. [CrossRef] 
23. Zhang, Y.J.; Ruan, J.J.; Huang, T.; Yang, X.P.; Zhu, H.Q.; Yang, G. Calculation of temperature rise in air-cooled induction motors through 3-D coupled electromagnetic fluid-dynamical and thermal finite-element analysis. IEEE Trans. Magn. 2012, 48, 1047-1050. [CrossRef]

24. Zhou, P.; Lin, D.; Xiao, Y. Temperature-dependent Demagnetization Model of Permanent Magnets for Finite Element Analysis. IEEE Trans. Magn. 2012, 48, 1031-1034. [CrossRef]

25. Zhou, Y.J.; Zhu, Z.Q. Torque Density and Magnet Usage Efficiency Enhancement of Sandwiched Switched Flux Permanent Magnet Machines Using V-Shaped Magnets. IEEE Trans. Magn. 2013, 49, 3834-3837. [CrossRef]

(C) 2017 by the authors. Licensee MDPI, Basel, Switzerland. This article is an open access article distributed under the terms and conditions of the Creative Commons Attribution (CC BY) license (http://creativecommons.org/licenses/by/4.0/). 